Available online at: http://ijmt.ir/browse.php?a code $=A-10-627-1$ \&sid=1\&s/c lang=en

\title{
Accidental Limit State of Submarine Pipeline: Trawl Gears Pull-Over Loads and Effect of Free Span
}

\author{
Sina Taghizadeh Edmollaii ${ }^{1}$, Pedram Edalat ${ }^{2 *}$ \\ ${ }^{1}$ M.Sc. Offshore Structural Engineering Department, Petroleum University of Technology, Mahmoudabad, Iran; \\ s.taghizadeh@mnc.put.ac.ir \\ ${ }^{2}$ Assistant Professor, Offshore Structural Engineering Department, Petroleum University of Technology, \\ Mahmoudabad,Iran; Edalat@put.ac.ir
}

\section{ARTICLE INFO}

Article History:

Received: 24 Apr. 2017

Accepted: 21 Sep. 2017

\section{Keywords:}

Submarine pipeline

Pull-over load

Free span

Finite element analysis

OrcaFlex

\begin{abstract}
Submarine pipelines failures lead to oil spills in water and may even lead to explosions with heavy financial and environmental damages. Trawl gear is one of the main factors in the failure of the submarine pipelines. In this paper, sensitivity analysis is performed on influence of height and span length alternations on the response of pipeline against the traction caused by trawling pull-over load. The FE model is presented using OrcaFlex software including modeling of seabed, pipeline and trawl gear parameters. To model soil and reinforced concrete, nonlinear parameters are considered. To verify the models, DNV-RP-F111 and results of modeling by SAGE Profile software is used. The results indicated that increase in span gap resulted in the increase in pipeline responses, but with the increase in span length, only the lateral displacement exhibited a considerable increment. Finally, Maximum time for pipeline to fail and system response to become greater than the standard level has been calculated.
\end{abstract}

\section{Introduction}

Today, sixty percent of the world's energy resources are composed of oil and gas. One of the safest and the most economical methods to transform oil and gas is using pipeline system. Prediction and prevention of pipeline failures during its assessed lifecycle has considerable importance from industrial experiences point of view. The most comprehensive database of offshore pipeline failure is available in the report of UK Health and Safety Executive PARLOC 2001 [1]. The PARLOC database indicates that about $53 \%$ of pipeline failures are caused by Accidental Limit State (ALS) factors in the submarine pipelines including trawling, dropped object, anchoring and natural hazards [1-3]. The pipeline damage due to the fishing gear is dependent on the type of fishing gear and the pipeline conditions, e.g. the weight and velocity of the fishing gear and the wall thickness, coating, and flexibility of the pipeline [4]. Several different types of fishing gear are used in the commercial fishing industry around the world. The three conventional types of trawl systems are shown in Figure 1. Based on the opening mechanism, the trawl bag is classified as [5]:

a) beam trawl by use of transverse beams,

b) twin trawl with clump weight, and c) Otter trawl by use of trawl boards which include V-Board, Polyvalent Board and Polyfoil Board.

Generally, assessment of the interaction between bottom trawl gears and pipelines is divided into three phases including [5]

i. Impact phase: In this phase, energy absorption and denting of the cross-section is focused due to the initial impact load.

ii. Pull-over phase: The "pull-over" phase is when the trawl gear drags over the pipeline on the seabed for a short time. This response is dynamic and requires the use of nonlinear finite element methods (NFEM) due to large lateral displacements, seabed contact, axial force changes and possible elasto-plastic material response.

iii. Hooking phase: In some cases, the trawl gear may actually be hooked under the pipeline and move it along with the trawl equipment, leading to a very severe loading situation. Hooking design load effects may be obtained by static nonlinear FE analysis of the pipeline subjected to a prescribed vertical lifting height.

In practical cases, pull-over loading is more likely than the other phases to be involved in trawl gear 
accident. So, this paper concern about the prediction of loads and responses in the pull-over phase.

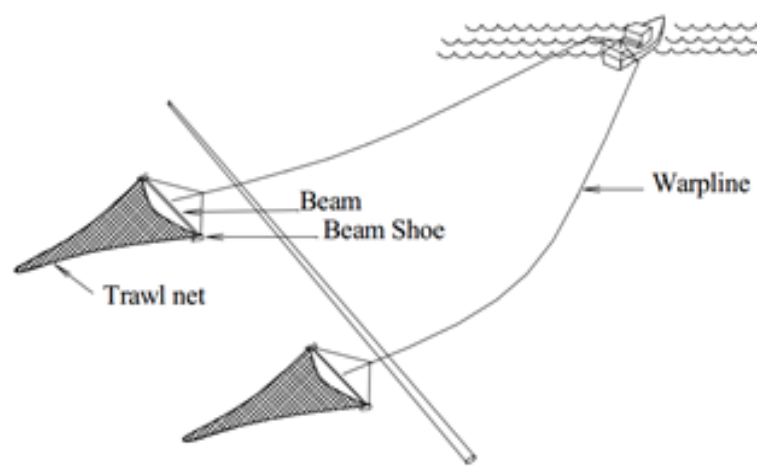

(a) Beam trawl

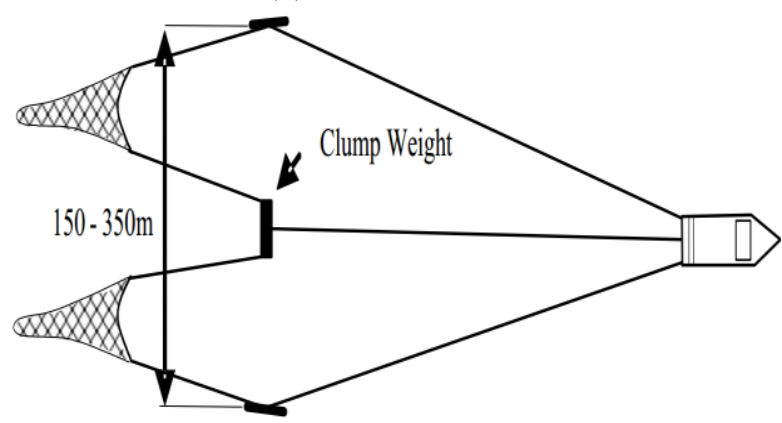

(b) Twin trawl

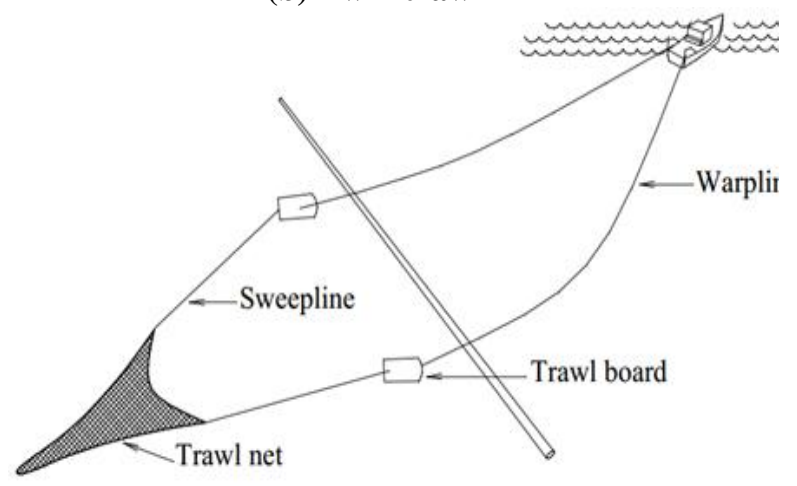

(c) Otter trawl

Figure 1. Different types of trawl gear [5].

Early research addressing the pull-over phase used to be based on laboratory and full-scale tests. Extensive testing was carried out in a Norwegian joint industry project (JIP) in the 1970s to study the interaction between pipelines and trawl gear [6-8]. Numerical methods for response prediction of pipelines subjected to prescribed pull-over loads were introduced in Bergan and Mollestad [9] and Guijt and Horenberg [10] in the 1980s. Verley [11] modeled the effect of free spans of up to $6 \mathrm{~m}$ height on trawl force. The results were presented including the maximum warp force, the maximum force applied to the pipeline, and the shape of the force-time trace. Fyrileiv [12] discussed trawl loads from clump weights and presented updated design approaches including pullover load estimation. The conclusion was that clump weights may govern the trawl design of pipelines, especially for trawl gear impact and pull-over. Igland and Soreide [13] performed non-linear dynamic finite element analysis for the interference between clump weight and pipeline on seabed using ANSYS software package. Results of the analysis revealed the pull-over force magnitude as well as the shape and duration of the clump weight's impact on the pipeline. Smallscale tests have been used to verify the FE model. Teigen et al. [14] developed FE simulation of the rather complex interaction between pipelines and trawl boards for the first time. Herlianto et al. [15] presented global response of subsea pipeline as a result of trawl gear pull-over loads. The external interference from trawl gear pull-over loads can create substantial imperfections or out-of-straightness on the pipeline and may generate global lateral buckling. The pull-over loads can also induce excessive bending moments and strains in the buckle region. Longva et al. [16] discussed that finite element analyses can be used to predict pull-over loads of a trawl board. A simulation model, which contained a polyvalent trawl board and a free spanning pipeline, was established. Several simulations were performed with span gaps between $0 \mathrm{~m}$ and $2 \mathrm{~m}$. In all simulations, the pull-over force and pipeline response were sampled.

In this research, displacement, bending moment and stress- strain of submarine pipeline under the effect of trawl pull-over load has been determined. Then, sensitivity analysis has been done for span gap and Span length. A case study of this work is the example provided in Appendix B of the DNV-RP-F111 [5] Recommend Practice on Trawl Gear Interference. The numerical modeling is performed by OrcaFlex software. The results of modeling by OrcaFlex are verified with DNV and results of modeling by SAGE Profile [17].

\section{Pull-Over load}

Pullover loads, namely horizontal and vertical forces from trawl boards, shall be applied as a single point load to the pipeline under consideration [18]. In this paper, trawling system type is otter trawl by use of polyvalent board. The pull-over loads for trawl board are calculated by using the following empirical formulae given in DNV-RP-F111 [5].

\subsection{Pull-over Loads for Trawl Board}

The maximum lateral pull-over load of a Trawl board $F_{p}$ is given by Eq. (1) [5]:

$$
F_{p}=C_{F} V \sqrt{m_{t} k_{w}}
$$

Warp line stiffness is obtained from Eq. (2):

$$
k_{w}=3.5 \times 10^{7} / L_{w}
$$

The coefficient $C_{F}$ for Polyvalent and rectangular boards is calculated by Eq. (3).

$C_{F}=8 .\left(1-e^{-0.8 \bar{H}}\right)$

In addition, the dimensionless height $\bar{H}$ is given by: 


$$
\bar{H}=\frac{H_{s p}+D_{o} / 2+0.2}{B}
$$

For trawl boards, the maximum vertical force acting in the downward direction can be estimated by Eq. (5):

$$
F_{z}=F_{p} \cdot\left(0.2+0.8 e^{-2.5 \bar{H}}\right)
$$

\subsection{Trawl Board Pull-over Duration}

The pull-over time $T_{p}$ is the total time where the trawl board is in contact with the pipe and it is given by Eq. (6) [5]:

$T_{p}=2 C_{F} \sqrt{\frac{m_{t}}{k_{w}}}+\frac{\delta_{p}}{V}$

According to DNV-RP-F111 assumed that:

$$
\frac{\delta_{p}}{V}=\frac{C_{F}}{5} \sqrt{\frac{m_{t}}{k_{w}}}
$$

For a polyvalent board the time history in Figure 2 applies for both the vertical and the horizontal pull-over load.

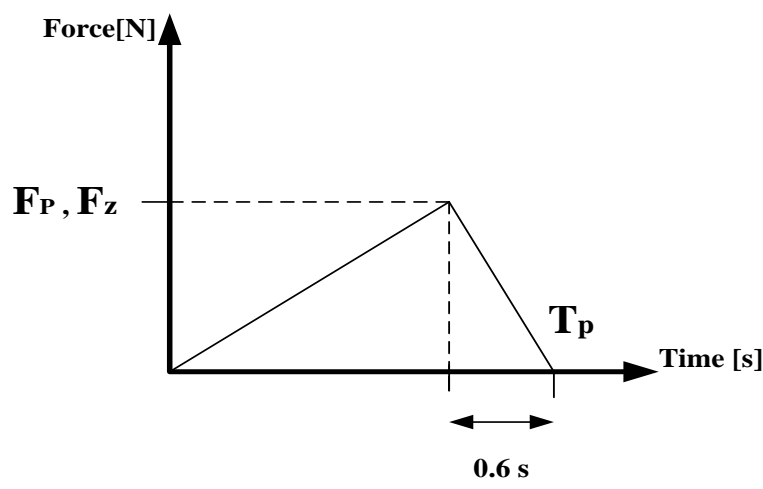

Figure 2. Polyvalent and rectangular pull-over force time history [5].

\section{Finite Element Analysis}

\subsection{Methodology}

According to Yong Bia, the summary of Finite Element Analysis for pull-over load is listed in Table $1[4]$.

Table 1. Summary of trawl FE analysis [4].

\begin{tabular}{ll}
\hline Characteristic & Pull-over \\
\hline Time & Second \\
\hline Load & $\begin{array}{l}\text { Time history of horizontal } \\
\text { \&vertical loads }\end{array}$ \\
\hline Solution & Time domain dynamic \\
\hline Design parameter & $\begin{array}{l}\text { Span gap } \\
\text { Span length }\end{array}$ \\
\hline $\begin{array}{l}\text { Design acceptance } \\
\text { criteria }\end{array}$ & $\begin{array}{l}\text { Allowable moment } \\
\text { Allowable Stress/strain }\end{array}$ \\
\hline
\end{tabular}

Pull-over load is estimated by modeling trawl gear interference as a dynamic load using non-linear finite element analysis. In this study, The FE analysis is carried out using the software OrcaFlex9.7a. The analysis process for trawl gear interaction with submarine pipelines is shown in Figure3.

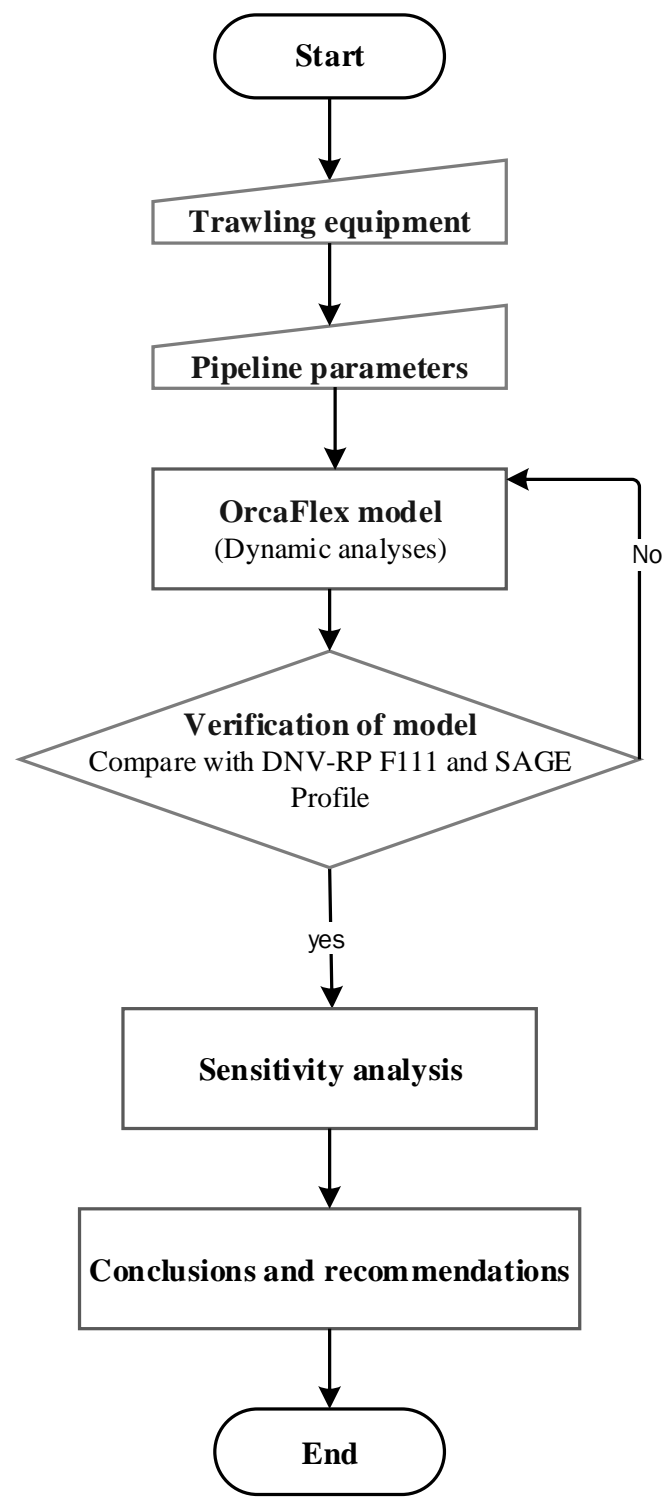

Figure 3. Flowchart of the analysis process used for trawl gear interaction with submarine pipelines.

\subsection{Finite Element Model}

The FE model in OrcaFlex includes modeling of seabed, pipeline parameter and trawl gear parameters. The considered trawl gear configuration is shown in Figures 4. In OrcaFlex, both static and dynamic analysis can be performed. There are two objectives for static analysis [19]:

- determining the equilibrium configuration of the system under weight, buoyancy, hydrodynamic drag, etc., and

- providing a starting configuration for dynamic simulation.

The dynamic analysis is a time simulation of the motions of the model over a specified period, starting 
from the position derived by the static analysis. The period of simulation is defined as a number of consecutive stages defined as input [19]. In this paper, OrcaFlex is used in a dynamic analysis of a case of trawl gear and pipeline interference by using implicit methods.

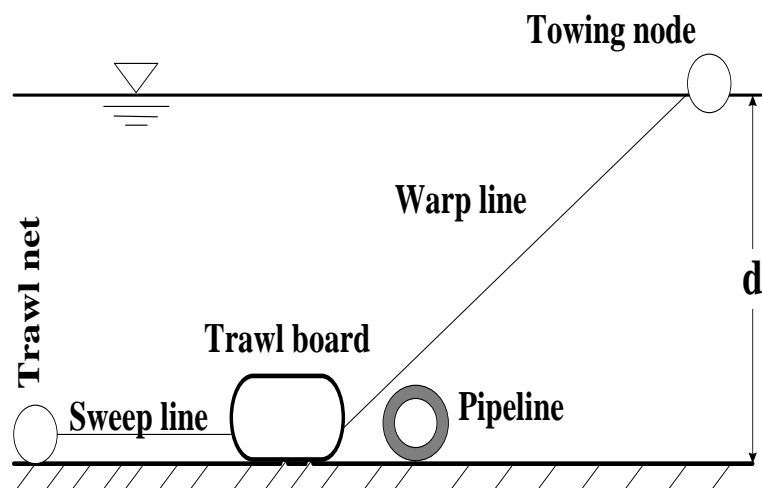

Figure 4. Trawl gear configuration, vertical plane.

\subsubsection{Seabed model}

In the event of trawling, sea bed friction resulting from soil-pipe interaction can have a major influence on pull-over loads when it is in full contact with the seabed as it develops a lateral restraint. However, this soil friction effects on free spanning pipelines are negligible, and hence, the soil friction for free span pipelines is not a significant parameter to consider [18]. OrcaFlex applies Coulomb friction between the line and the seabed. The applied friction force never exceeds $\mu R$ where $R$ is the seabed reaction force and $\mu$ is the friction coefficient. Lines lying on the seabed often move axially more readily than laterally. To enable this effect to be modeled, different friction coefficients $\mu$ can be specified in normal (i.e. lateral) and axial motion relative to the line direction. For intermediate directions of motion, OrcaFlex interpolates between these two values to obtain the friction coefficient $\mu$ to be used [19]. The soil condition for the case study in this paper is shown in Table 2. Soil stiffness is applicable only to pipelines resting on the seabed. No soil stiffness is assumed for pipeline free spans. A flat seabed is a simple plane which is modeled for the pipeline with span gaps of 0 $\mathrm{m}$. A profiled seabed is one where the shape is specified by a $2 \mathrm{D}$ profile in a particular direction. Normal to that profile direction, the seabed is horizontal. A profiled seabed is designed for the pipeline with free span.

Table 2. Soil condition.

\begin{tabular}{lll}
\hline Parameter & Value & Unit \\
\hline Sand, friction angle, $\Phi$ & 35 & {$[\mathrm{deg}]$} \\
\hline Axial friction coefficient & 0.4 & \\
\hline Lateral friction coefficient & 0.6 & \\
\hline
\end{tabular}

\subsubsection{Pipeline model}

A 14 in OD line pipe was modeled as a $13 \mathrm{~km}$ straight pipeline. The pipeline and trawl gear interference is assumed to occur at a location where the water depth is $300 \mathrm{~m}$. The detail of pipeline parameter is shown in Table 3. According to Figure 5, pipeline ends boundary conditions are considered as fixed supported.

OrcaFlex uses a finite element model for a line pipe as shown in Figure 6. The line is divided into line segments, which are then modeled by straight mass less two nodes element with $6 \mathrm{DOF}$ at each node. The elements can model the axial and torsional properties of the line. The other properties such as mass, weight, and buoyancy are all lumped to the nodes, as indicated in Figure 6. In this study, the pipeline is a homogeneous standard steel pipe type with predefined material properties including material density, Young's modulus and Poisson ratio [19].

Table 3. Pipeline data.

\begin{tabular}{lll}
\hline Parameter & Value & Unit \\
\hline Outer diameter & 356 & {$[\mathrm{~mm}]$} \\
\hline Wall thickness & 16 & {$[\mathrm{~mm}]$} \\
\hline Corrosion allowance & 3 & {$[\mathrm{~mm}]$} \\
\hline Steel quality & SML450I U & \\
\hline $\begin{array}{l}\text { Specified minimum yield } \\
\text { stress }\end{array}$ & 450 & {$\left[\mathrm{~N} / \mathrm{mm}^{2}\right]$} \\
\hline $\begin{array}{l}\text { Specified minimum tensile } \\
\text { strength }\end{array}$ & 535 & {$\left[\mathrm{~N} / \mathrm{mm}^{2}\right]$} \\
\hline Coating type & Concrete & \\
\hline Coating thickness & 40 & {$[\mathrm{~mm}]$} \\
\hline Coating specific weight & 1900 & {$\left[\mathrm{~kg} / \mathrm{m}^{3}\right]$} \\
\hline Drag coefficient & 2.0 & \\
\hline Added mass coefficient & 2.0 & \\
\hline Content & Oil & {$\left[\mathrm{kg} / \mathrm{m}^{3}\right]$} \\
\hline Content specific weight & 800 & {$\left[{ }^{\circ} \mathrm{C}\right]$} \\
\hline Design temperature & 40 & {$[\mathrm{bar}]$} \\
\hline Design pressure & 100 & {$\left[{ }^{\circ} \mathrm{C}\right]$} \\
\hline Water depth & 300 & \\
\hline Ambient temperature & 5 & \\
\hline Safety class & Normal & \\
\hline Load effect factor & 1.1 & 1.07 \\
\hline Load effect factor & & \\
\hline
\end{tabular}

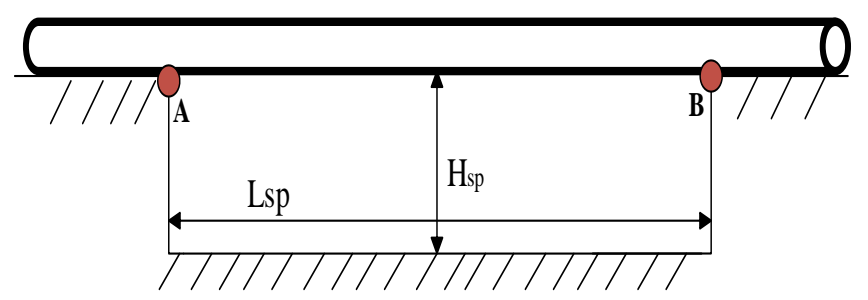

Figure 5. Boundary condition end pipeline. 


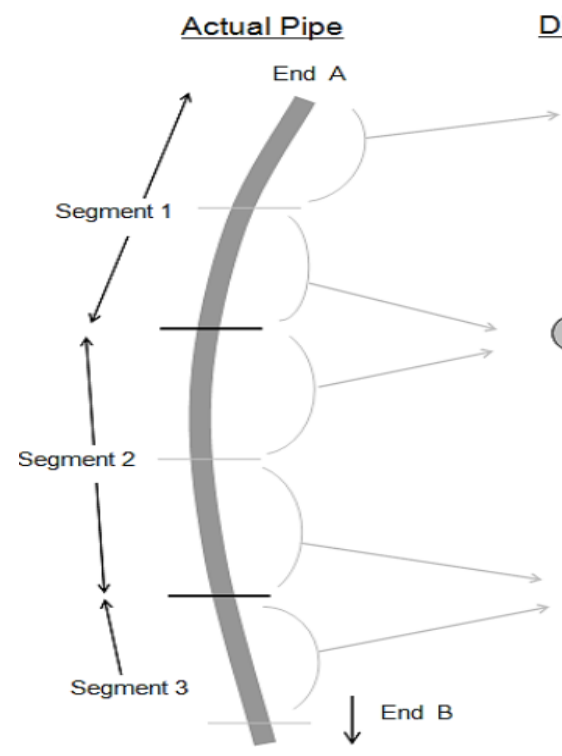

Discretised Model

Figure 6. OrcaFlex line element model [19].

\subsubsection{Trawling equipment model}

In this paper according to Figure 7, polyvalent and rectangular trawl board was used in the FE analysis. This type of trawl board has been found to give the highest loads on pipelines [5]. The properties of polyvalent and rectangular trawl boards are presented in Table 4.

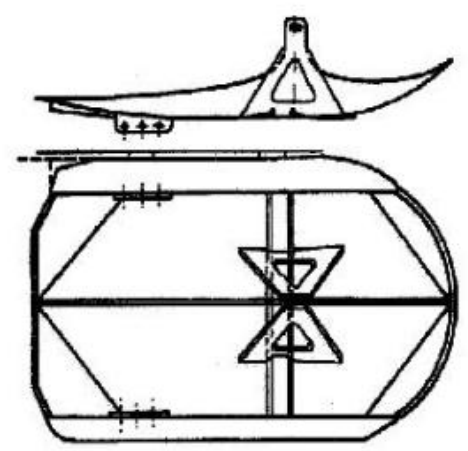

Figure 7. Polyvalent and rectangular trawl boards [4].

The elastic stiffness of the warp line in OrcaFlex is obtained by Eq. (2). The warp line tension is given by [19]:

$t=K \varepsilon+C K \frac{d \varepsilon}{d t}$

Warp line strain rate is obtained using Eq. (8) for each loading and unloading in every time step.
Table 4. Polyvalent trawl gear data.

\begin{tabular}{lll}
\hline Parameter & Value & Unit \\
\hline Trawl board steel mass & 4000 & {$[\mathrm{~kg}]$} \\
\hline Trawl size (length $\times$ height) & $4.5 * 3.5$ & {$[\mathrm{~m}]$} \\
\hline Trawl velocity & 2.8 & {$[\mathrm{~m} / \mathrm{s}]$} \\
\hline Warp line length & 900 & {$[\mathrm{~m}]$} \\
\hline Warp line diameter & 38 & {$[\mathrm{~mm}]$} \\
\hline Load effect factor & 1.1 & \\
\hline Condition load effect factor & 1.07 & \\
\hline
\end{tabular}

\subsection{OrcaFlex model}

In order to perform sensitivity analysis on the response of submarine pipeline under the influence of variations of height and span length, the pipeline is modeled with different heights of free span $(0,1$ and 2 $\mathrm{m})$ and different lengths of free span (20, 60 and 100 $\mathrm{m})$, which is pulled in the direction of 90 degrees by trawl gear. Interaction between pipeline and trawl board for span gap $1 \mathrm{~m}$ and span length $100 \mathrm{~m}$ at three main time intervals - before, during and after collision - is shown in Figure 8.
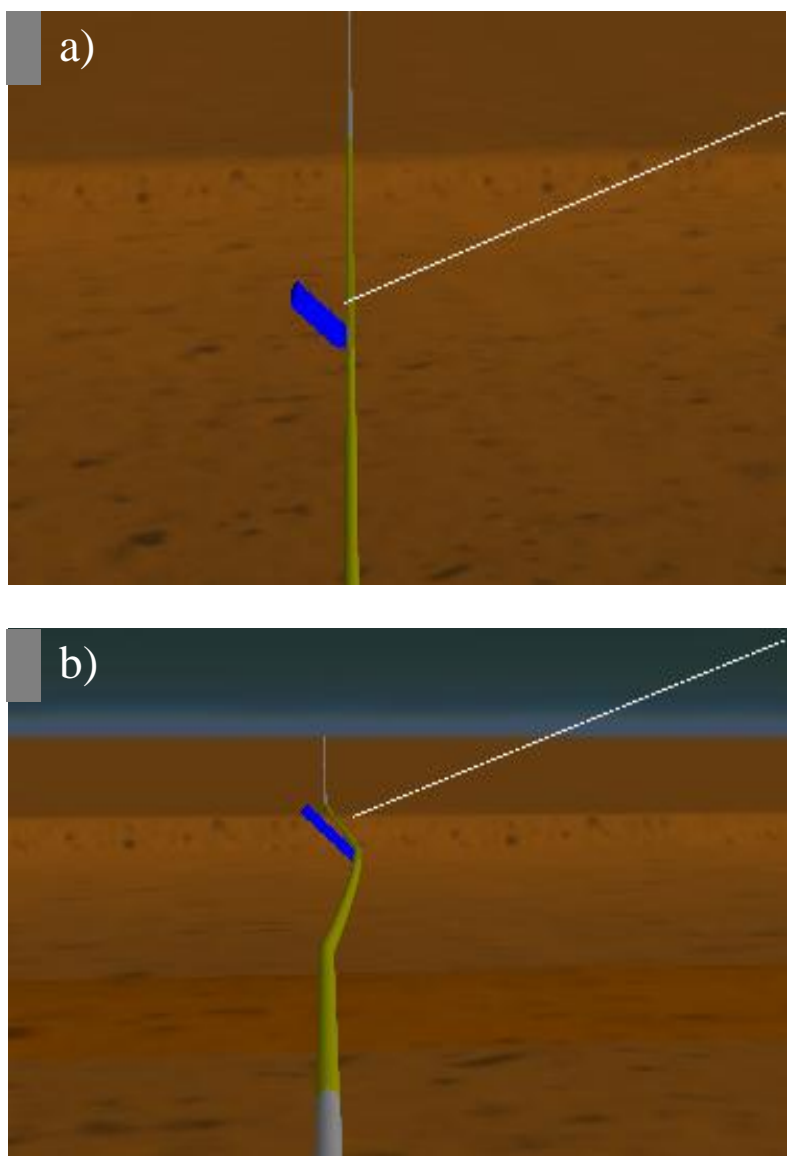


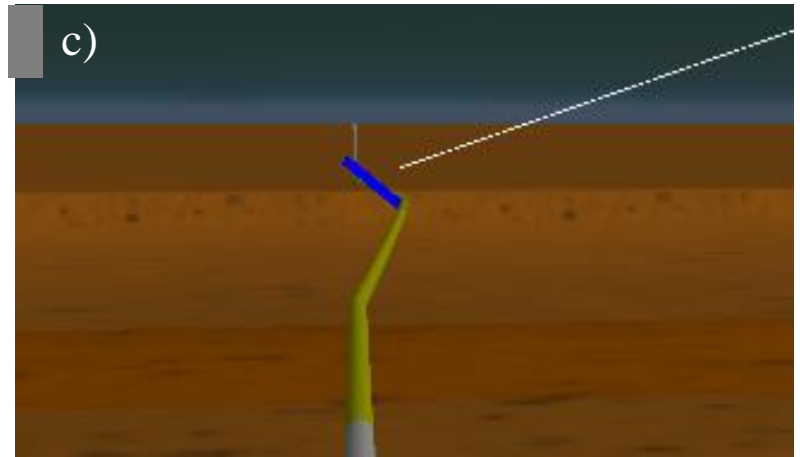

Figure 8. Trawl board and pipeline simulation a) before, b) during and c) after collisions.

\section{Results and Discussion}

According to Eq. (1-5), pull-over load and time duration depend on span gap. Therefore, for any span gap will be pull-over load and time duration that is shown in Table 5. The results presented for four subsequent trawl pull-over load.

Table 5. Pullover forces according to DNV-RP-F111 for span gap $0,1,2 \mathrm{~m}$.

\begin{tabular}{lll}
\hline Hsp [m] & $\mathbf{F}[\mathbf{k N}]$ & $\mathbf{T} \mathbf{p}[\mathbf{s}]$ \\
\hline 0 & 48.6 & 0.98 \\
\hline 1 & 133.767 & 2.7 \\
\hline 2 & 187.13 & 3.77 \\
\hline
\end{tabular}

\subsection{Verification of model}

In this research $\mathrm{FE}$ modeling has been done using OrcaFlex software. For verification purpose, the displacement responses of pipeline resulted from OrcaFlex modeling is compared with the DNV-RPF111 and the results of modeling by SAGE Profile software proposed by Van Den et al. [17].

As shown in Figure 9, OrcaFlex predicts the response with similar trend and acceptable divergence.

\subsection{Response of submarine pipeline under pull- over load}

The effect of variation span gap on the pipeline response is investigated considering constant span length equal to 20 meters and span gap changes as 0,1 and 2 meters. As shown in Figure 10, as the span gap is increased, the friction soil decreases resulting in a considerable amplification in responses with different trend as compared to span gap zero meter, which is increasing over time.

In initial time steps of system response of dynamic analysis, there is a minor difference between span gap one and two meter, which shows an increasing rate as time, passes.

The results indicating the effect of span length on response of pipeline were presented in Figure 11 for span gap one meter. The displacement of pipeline under the action of pull-over load strictly depends on the length of the free span and as the span length is increased, the oscillation period and amplitude is increased sharply. Bending moment and strain response are not affected by changing free span length.

The amplitude changes in system response are presented in Figure 12. Changing the span gap from zero to one meter leads to more changes in system response than changing from one to two meter does. This means when span gap changes from zero to one meter it is more expectable that pipeline fails. As the time passes with dynamic analysis, the response difference between span gap changes becomes greater. In other word, the diagram diverges. Pipeline response increases by increasing the span gap. In other words, pipeline fails sooner. By increasing the span length, only lateral displacement increases considerably while strain and bending moment do not change relatively.

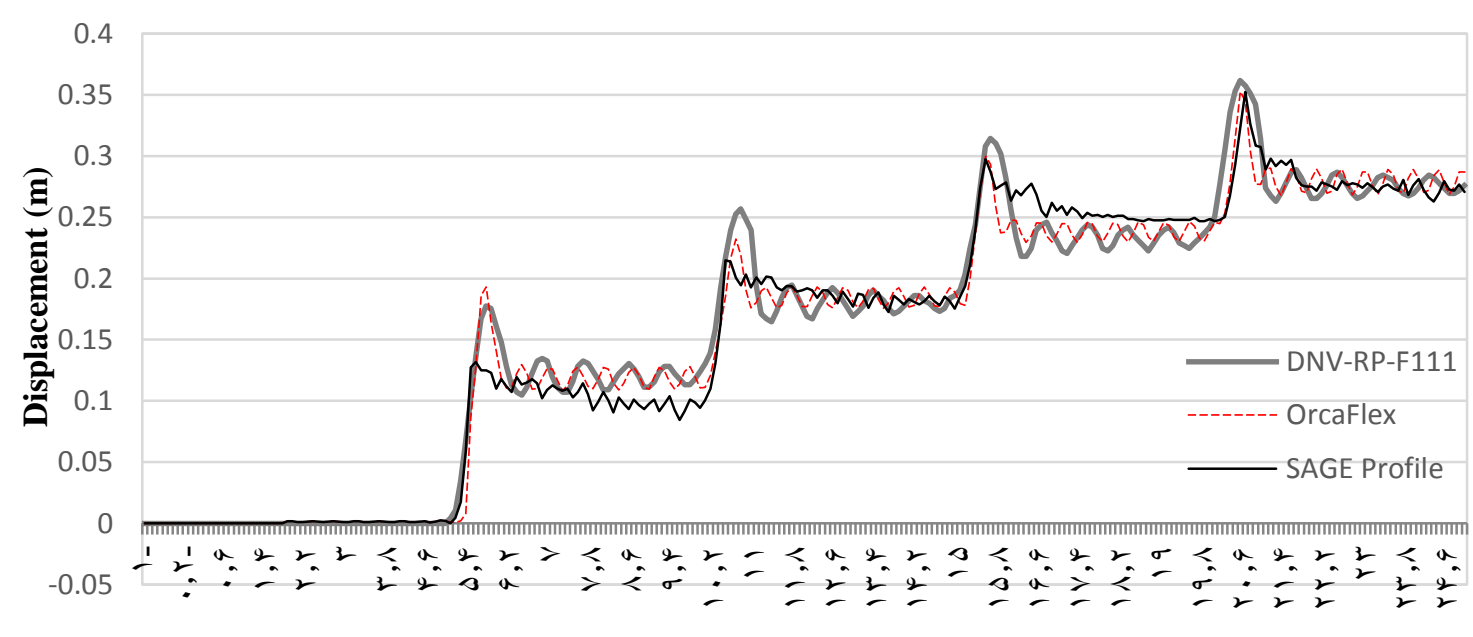

Pull-over time (s)

Figure 9. Pipeline response to subsequent trawl gear pull-over load. 

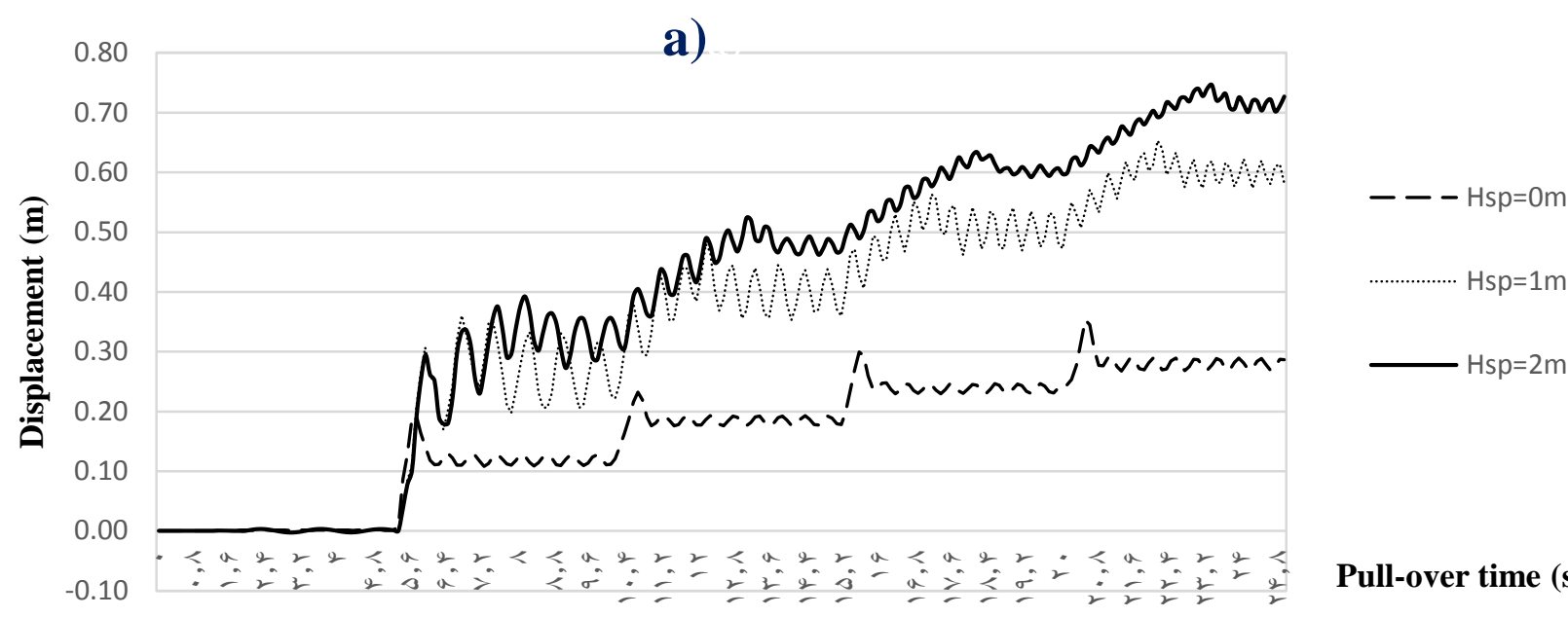

Pull-over time (s)

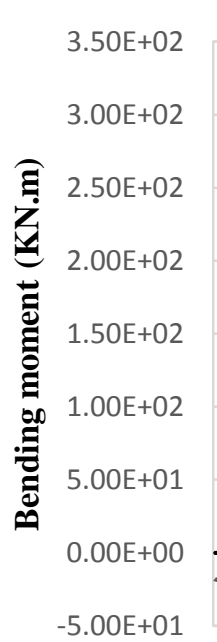

b)
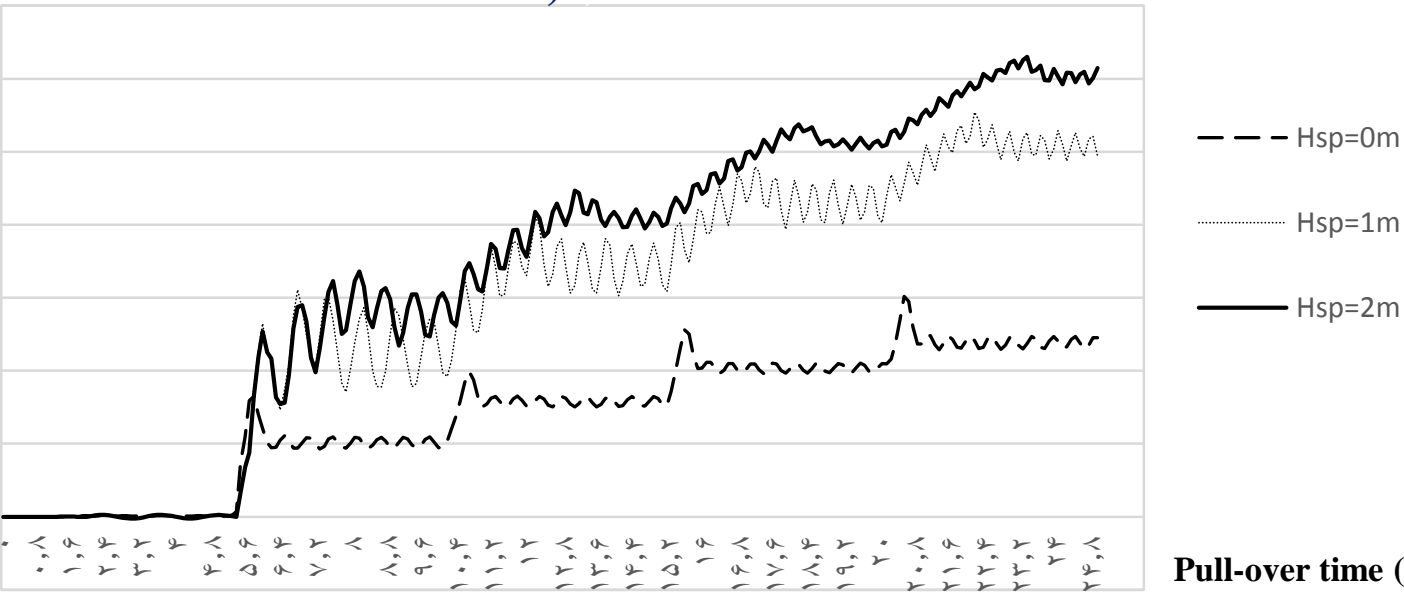

Pull-over time (s)

c)

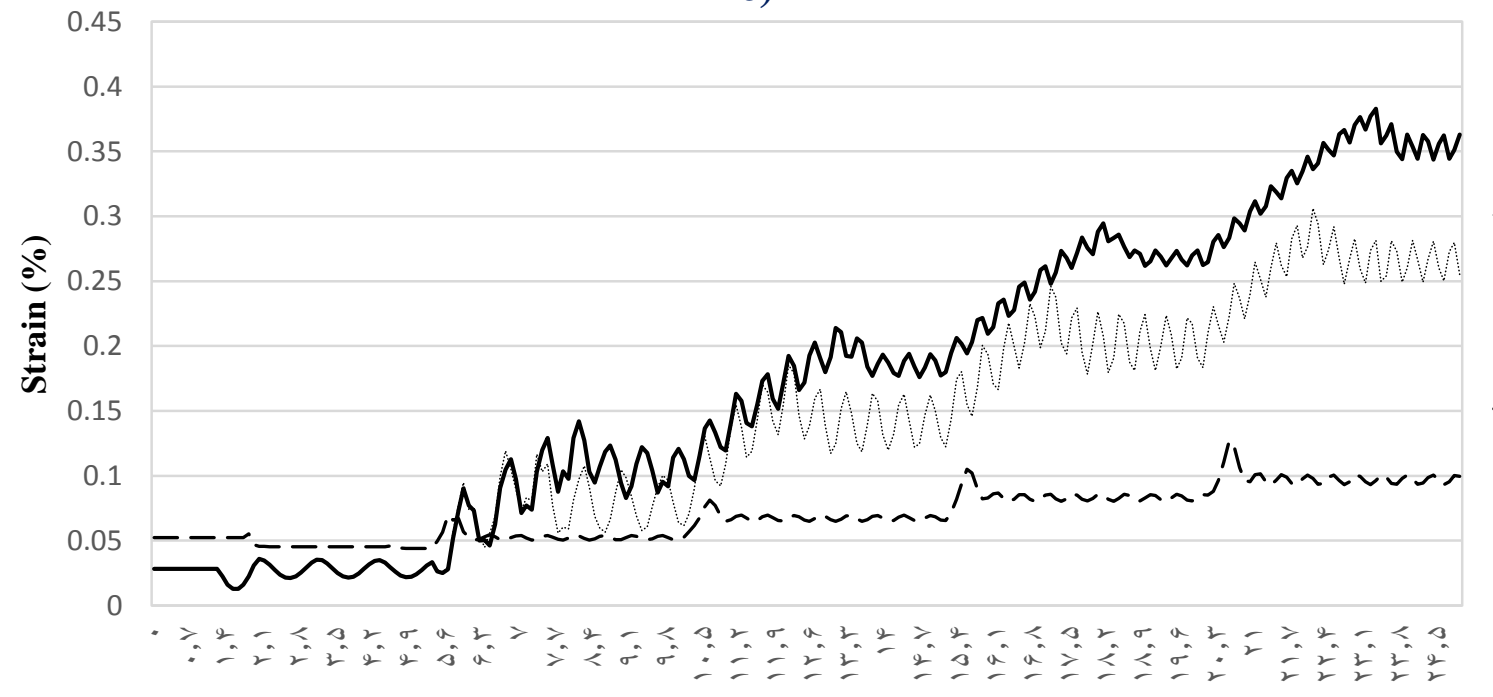

Pull-over time (s)

Figure 10. Submarine pipeline response under trawl gear pull-over load for Lsp=20m: a) Displacement, b) Bending moment, and c) Strain. 

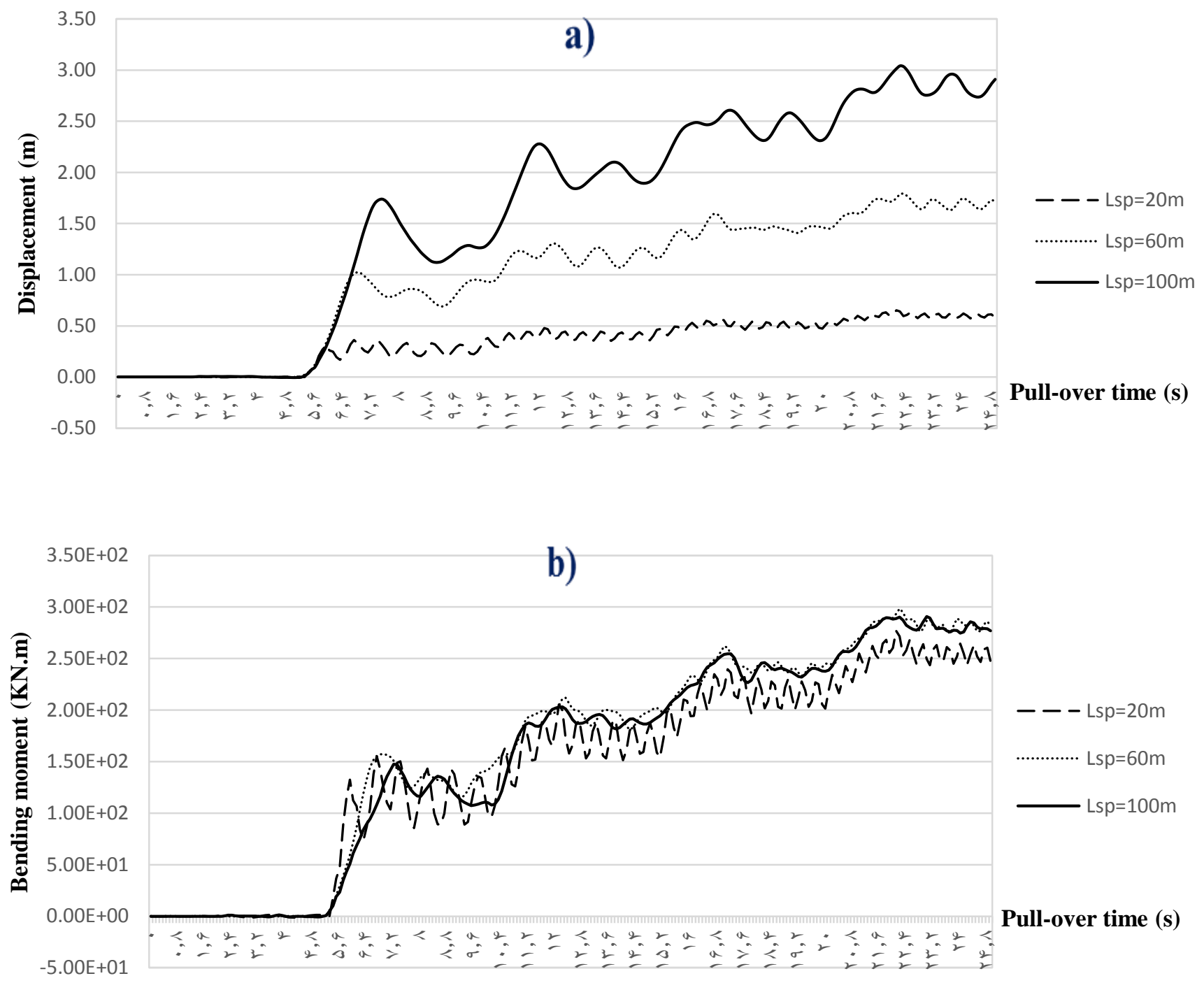

c)

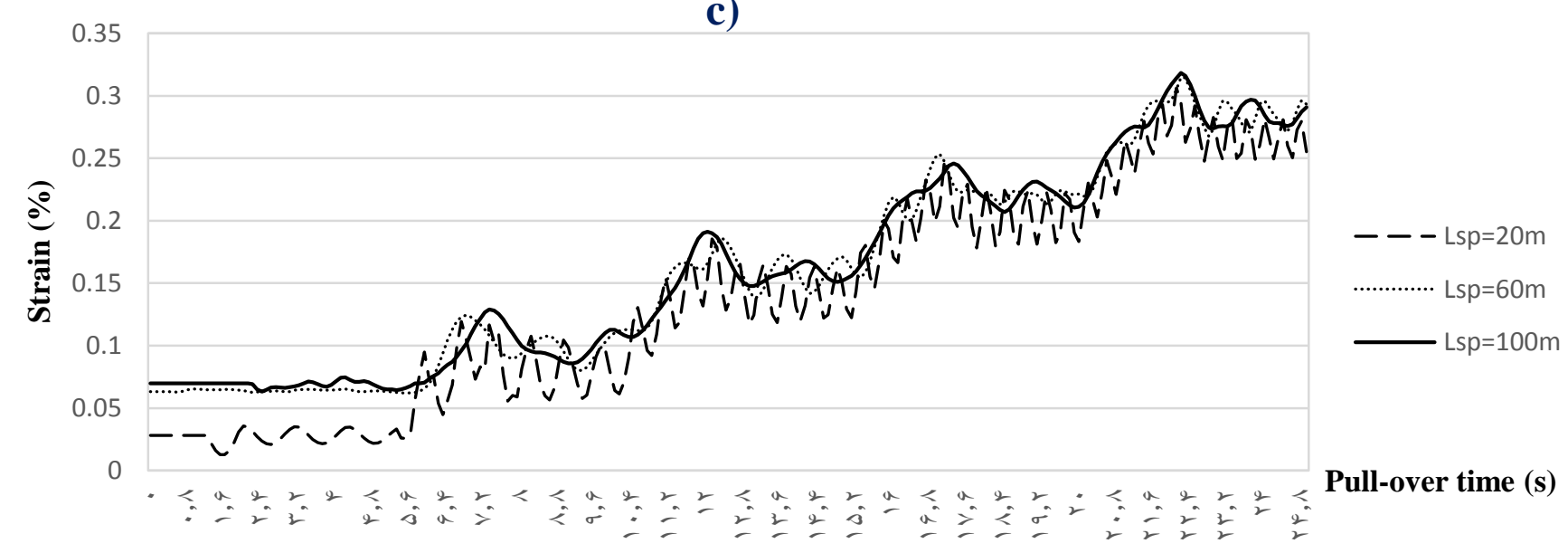

Figure 11. Submarine pipeline response under trawl gear pull-over load for Hsp=1 m: a) Displacement, b) Bending moment, and c) Strain. 


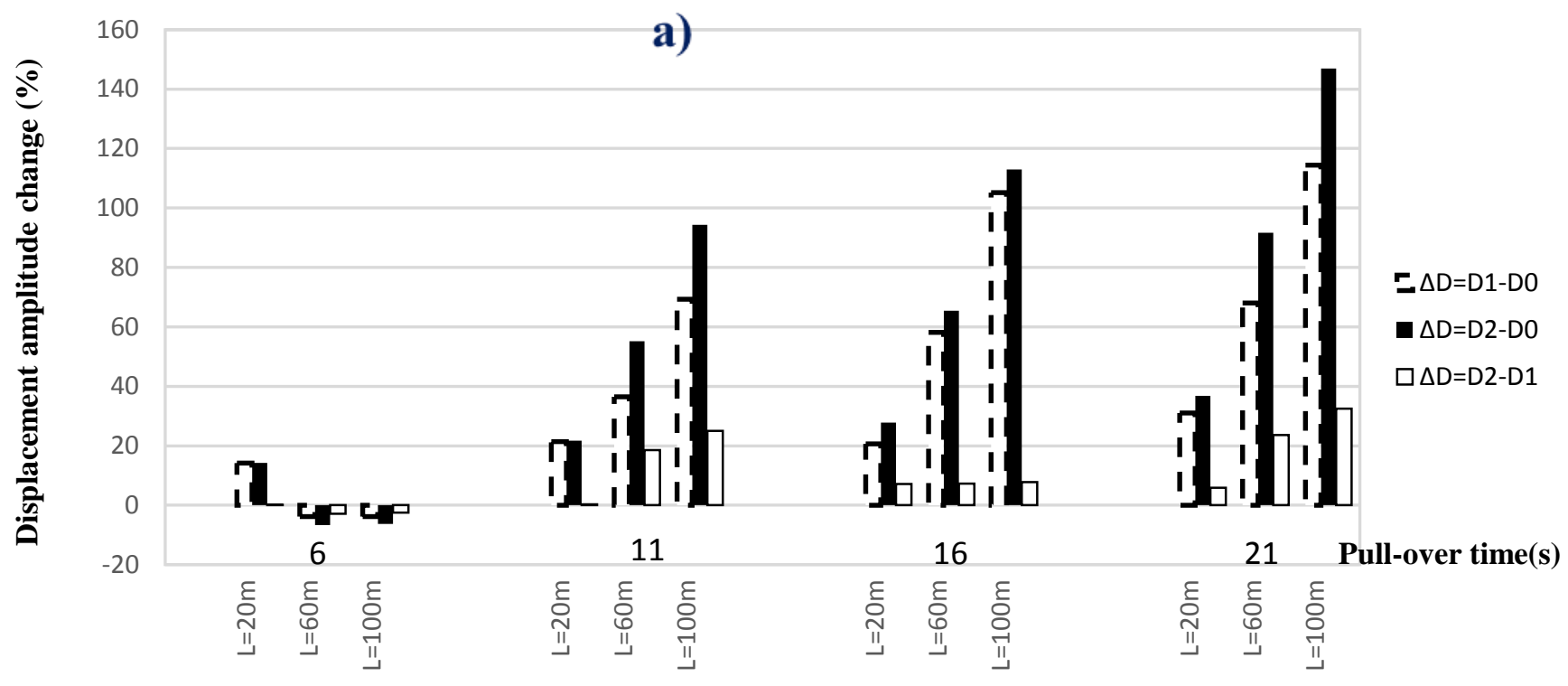

b)

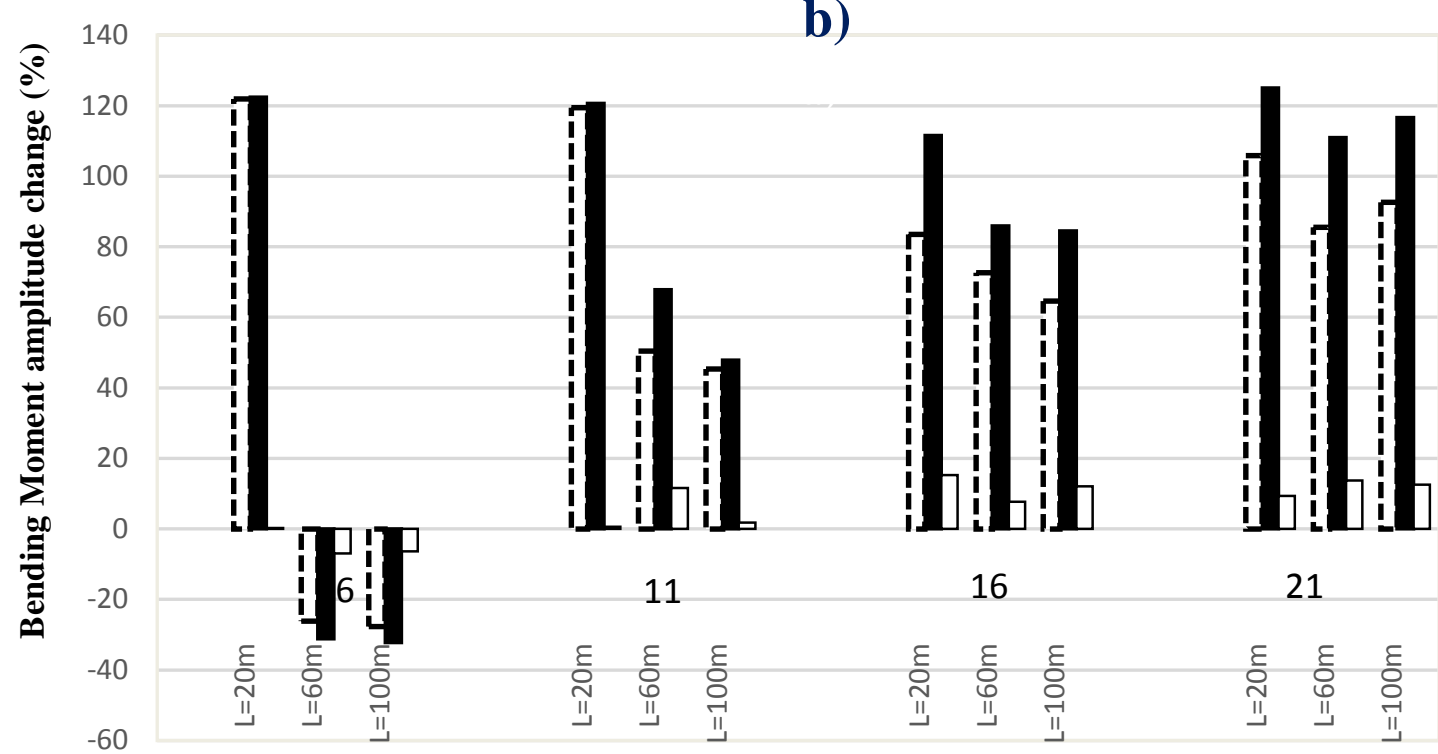

I $\triangle \mathrm{BM}=\mathrm{BM} 1-\mathrm{BM} 0$

- $\triangle \mathrm{BM}=\mathrm{BM} 2-\mathrm{BM} 0$

$\square \triangle B M=B M 2-B M 1$

Pull-over time(s)

250

c)
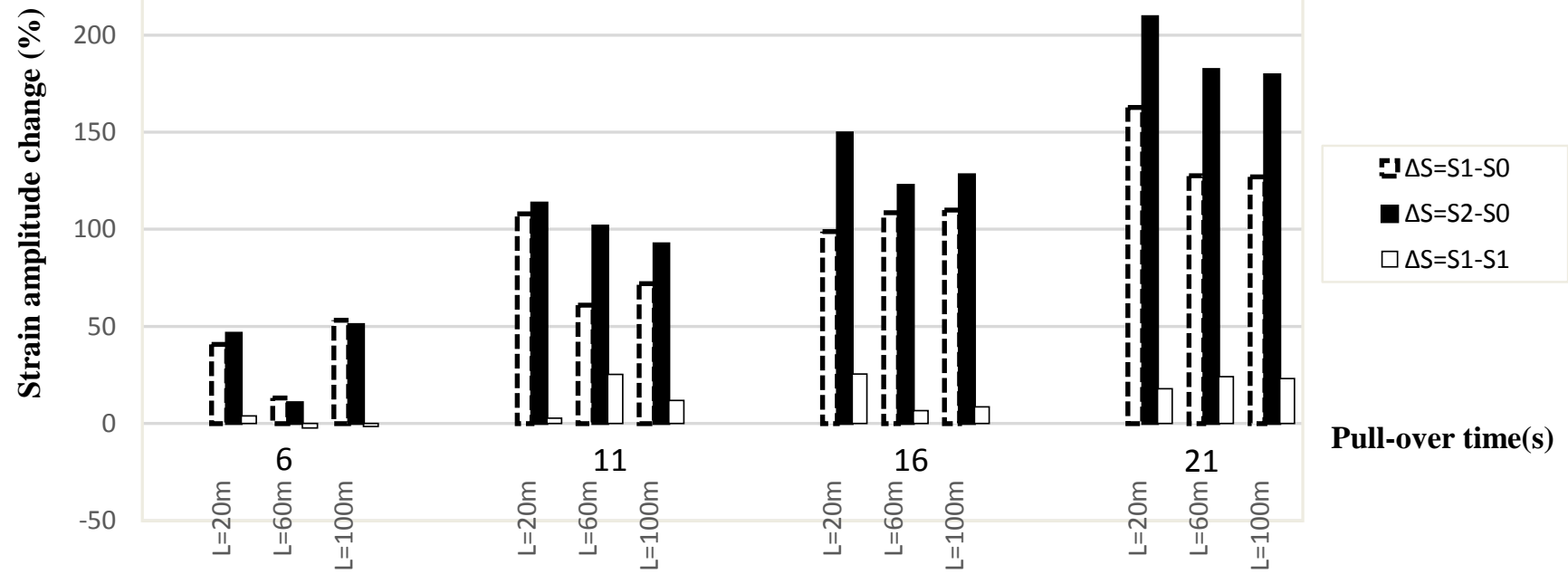

Figure 12. Amplitude changes in system response presented in term of percentage: a) Displacement amplitude change, b) Bending moment amplitude change, and c) Strain amplitude change. 


\subsection{Checking design acceptance criteria for trawling pull-over load}

According to Table 1, allowable Moment and allowable stress/strain are design acceptance criteria for trawling pull-over load. The amount of allowable moment is obtained from load controlled combined buckling check in accordance with DNV-OS-F101, which is shown in Eq. (9). The amount of allowable stress/strain is obtained from displacement controlled combined buckling check in accordance with DNVOS-F101, which is shown in Eq. (10). For the case study of this work, allowable moment and allowable strain are $571.2[\mathrm{kN} / \mathrm{m}]$ and $0.572[\%]$, respectively.

$$
\begin{aligned}
& M_{\text {allowable }}=\left[\frac{\alpha_{c}}{\gamma_{m} \cdot \gamma_{s c}} \cdot \sqrt{1-\left(\alpha_{p} \cdot \frac{p_{i}-p_{e}}{\alpha_{c} \cdot p_{b}}\right)^{2}}\right. \\
& \left.-\frac{\gamma_{m} \cdot \gamma_{s c} \cdot s_{d n}^{2}}{\alpha_{c}}\right] \cdot M_{p} \cdot \frac{1}{\gamma_{f} \cdot \gamma_{c}} \\
& \varepsilon_{s d}=\frac{0.78}{\gamma_{\varepsilon} \cdot \gamma_{s c}}\left(\frac{t}{D}-0.01\right) \cdot\left(1+5.75 \cdot \frac{p_{\min }-p_{e}}{p_{b}}\right) \cdot \alpha_{h}{ }^{-1.5} \cdot \alpha_{g w}
\end{aligned}
$$
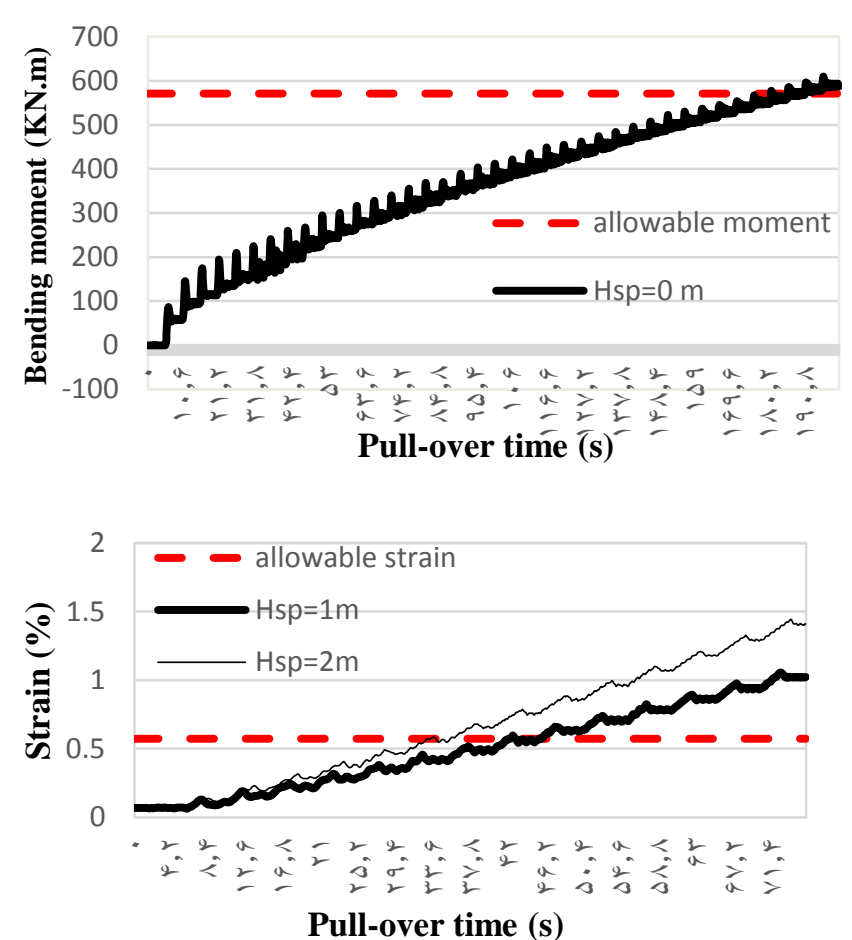

Pull-over time (s)

Figure 13. Comparison between Submarine pipeline response and design acceptance criteria trawl gear pull-over load for Lsp=100m.

Table 6. Endurance time According to span gap.

\begin{tabular}{ccc}
\hline Hsp [m] & Bending moment Endurance time[s] & Strain Endurance time[s] \\
\hline 0 & 191 & 141 \\
\hline 1 & 73 & 48 \\
\hline 2 & 53 & 36 \\
\hline
\end{tabular}

As the results show, submarine pipeline response under trawling pull-over load is more sensitive to the span gap than to the free span length. This sensitivity is more considerable when the span gap is changed from zero to one meter than when it is changed from one to two meter. Because of the soil friction, Endurance time for passing the design acceptance eria when span gap is approximately zero meter, three times greater than the cases in which free gap is one or two meter. Based on these results, one should notice the importance of height over length in primary design of free span for pipelines.
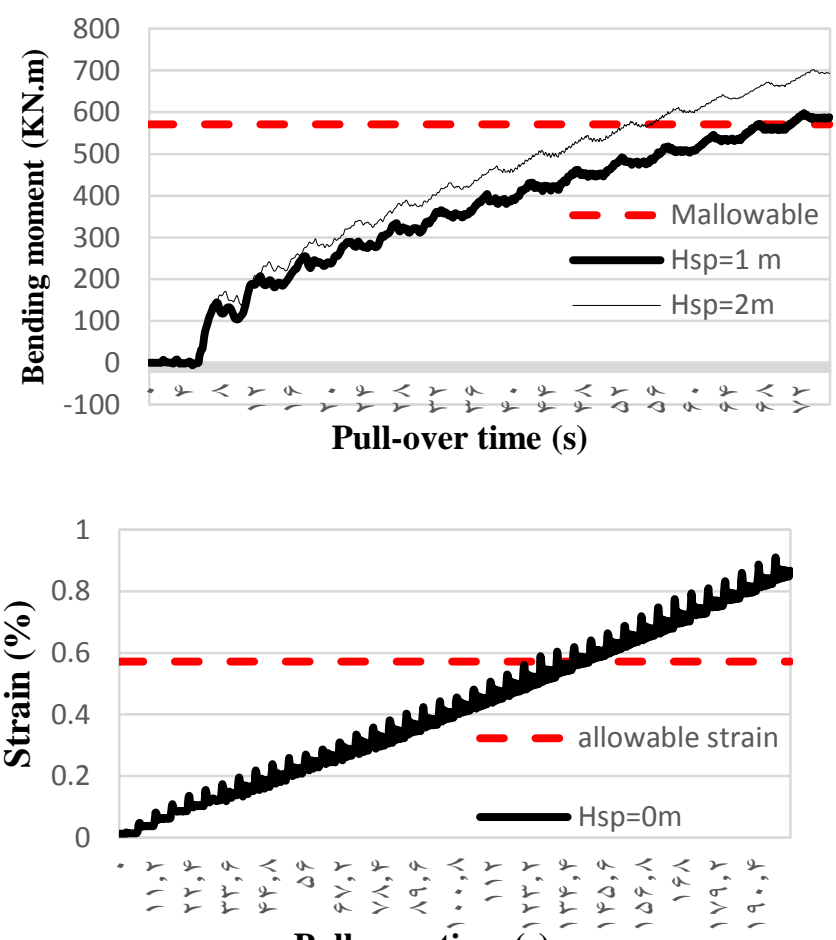

Pull-over time (s) 


\begin{tabular}{|c|c|}
\hline$F_{p}$ & maximum lateral pull-over load $[\mathrm{kN}]$ \\
\hline$k_{w}$ & Warp line Stiffness $[\mathrm{kN}]$ \\
\hline$V$ & Trawling velocity $[\mathrm{m} / \mathrm{s}]$ \\
\hline$m_{t}$ & Trawl board steel mass $[\mathrm{kg}]$ \\
\hline$L_{w}$ & Length of the warp line $[\mathrm{m}]$ \\
\hline$H_{s p}$ & Span gap $[\mathrm{m}]$ \\
\hline$D_{o}$ & Pipe outer diameter $[\mathrm{m}]$ \\
\hline $\begin{array}{l}B \\
C_{F}\end{array}$ & $\begin{array}{l}\text { Half-height of the trawl board }[\mathrm{m}] \\
\text { Coefficient }\end{array}$ \\
\hline $\bar{H}$ & Dimensionless height \\
\hline$F_{z}$ & Maximum vertical force $[\mathrm{kN}]$ \\
\hline$T_{p}$ & Pull-over time [s] \\
\hline$\delta_{p}$ & $\begin{array}{l}\text { Displacement of the pipe at the point of } \\
\text { interaction }\end{array}$ \\
\hline$t$ & wire tension $[\mathrm{kN}]$ \\
\hline$K$ & Wire Stiffness $[\mathrm{kN}]$ \\
\hline$\varepsilon$ & Wire Strain [m] \\
\hline C & Material damping factor \\
\hline$\frac{d \varepsilon}{d t}$ & Wire Strain Rate $[\mathrm{m} / \mathrm{s}]$ \\
\hline Lsp & Span length $[\mathrm{m}]$ \\
\hline$M_{\text {allowable }}$ & Allowable moment \\
\hline$M_{p}$ & Plastic moment capacities \\
\hline$p_{i}$ & Internal pressure \\
\hline$p_{e}$ & External pressure \\
\hline$p_{\min }$ & Minimum internal pressure \\
\hline$p_{b}$ & Burst pressure \\
\hline$S_{d n}$ & Normalized effective force \\
\hline$\alpha_{c}$ & Flow stress parameter \\
\hline$\alpha_{p}$ & Pressure factor \\
\hline$\varepsilon_{s d}$ & Characteristic bending strain resistance \\
\hline$\gamma_{s c}$ & Safety class resistance factor \\
\hline$\gamma_{m}$ & Material resistance factor \\
\hline$\gamma_{f}$ & Load effect factor for functional load \\
\hline$\gamma_{\varepsilon}$ & Resistance factor \\
\hline$\alpha_{h}$ & Yield strength / tensile strength ratio \\
\hline
\end{tabular}

$\alpha_{g w} \quad$ Girth weld factor (strain resistance)

\section{References}

1- Kawsar, M. R. U., Youssef, S. A., Faisal, M., Kumar, A., Seo, J. K., \& Paik, J. K. (2015). Assessment of dropped object risk on corroded subsea pipeline. Ocean Engineering, 106, 329-340. [DOI: 10.1016/j.oceaneng.2015.06.056]

2- Mustafina, A., (2015), Anchor Damage Assessment of Subsea Pipelines - Optimization of Design Methodology, (Master's thesis in Offshore technology, University of Stavanger, Norway), Retrieved from http://hdl.handle.net/11250/1248742. 3- DNV GL, (2012), DNV-OS-F101 Submarine Pipeline Systems, Det Norske Veritas, Norway. https://rules.dnvgl.com/docs/pdf/DNV/codes/docs/20 12-08/Os-F101.

4- Bai, Y., Bai, Q., (2005), Subsea pipelines and risers, Oxford UK: Elsevier Ltd, p. 173-194.

5- DNV GL, (October2010), DNV-RP-F111 Interference between Trawl Gear and Pipelines, Det Norske Veritas, Norway. https://rules.dnvgl.com/docs/pdf/DNV/codes/docs/.../ RP-F111

6- Gjørsvik, O., Kjeldsen, S., Lund, S., (1975), Influences of bottom trawl gear on submarine pipelines, seventh annual offshore technology conference, p. 337-345.

7- Carstens, T., Kjeldsen, S., Gjørsvik, O., (1976), The conflict between pipelines and bottom trawls some results from laboratory and field tests, Offshore north sea technology conference and exhibition.

8- Moshagen, H., Kjeldsen, S., (1980), Fishing gear loads and effects on submarine pipelines, Twelfth annual offshore technology conference, p. 383-392.

9- Bergan, P.G., Mollestad, E., (1982), Impactresponse behavior of offshore pipelines, Journal of Energy Resour-ASME, 104:325-9 [DOI: 10.1115/1.3230423]

10- Guijt, J., Horenberg, J.A.G., (1987), Recent investigations concerning the effect of bottom trawl gear crossings on submarine pipeline integrity, Nineteenth annual offshore technology conference, $\mathrm{p}$. 573-580. [DOI: 10.4043/5616-MS]

11- Verley, R.L.P., Moshagen, B.H., (1992), trawl forces on free-spanning pipelines. International Journal of Offshore and Polar Engineering, ISOPE92-02-1-024.

12- Fyrileiv, O., Askheim, D., Verley. R., Rolsdorph, H., (2006), Pipeline-Trawl Interaction: Effect of Trawl Clump Weights, ASME. International Conference on Offshore Mechanics and Arctic Engineering. [DOI: 10.1115/OMAE2006-92128] 13- Igland, R.T., Soreide, T., (2008), Advanced Pipeline Trawl Gear Impact Design, ASME, International Conference on Offshore Mechanics and 
Arctic Engineering, Volume 3: Pipeline and Riser Technology. [DOI: 10.1115/OMAE2008-57354]

14- Teigen, P., Ilstad, H., Levold, E., \& Hansen, K. (2009, January 1), Hydrodynamical Aspects of

Pipeline Over trawling, International Society of Offshore and Polar Engineers, ISOPE-I-09-061.

15- Herlianto, I., Chen, Q., Karunakaran, D., (2012), Lateral Buckling Induced by Trawl Gears Pull-Over Loads on High Temperature/High Pressure Subsea Pipeline, ASME, International Conference on Offshore Mechanics and Arctic Engineering, Volume 3: Pipeline and Riser Technology. [DOI: 10.1115/OMAE2012-83298]

16- Longva, V., Saevik, S., Levold, E., Ilstad, H., Teigen, P., (2011), Dynamic Simulation of FreeSpanning Pipeline Trawl Board Pull-Over, ASME,
International Conference on Offshore Mechanics and Arctic Engineering, Volume 4: Pipeline and Riser Technology. [DOI: 10.1115/OMAE2011-49592] 17- Van den Abeele, F., Galvan, B.C., Ramos, P., Muylle, J., (2013), Numerical simulation of the interference between trawl gear and offshore pipelines, $6^{\text {th }}$ International Pipeline Technology Conference, Ostend.

18- Yohannes, B., (2012), Trawl Gear interaction with Subsea Pipelines, (Master's thesis in Offshore technology, University of Stavanger, Norway), Retrieved from http://hdl.handle.net/11250/183133. 19- OrcaFlex manual version 9.7a, Orcina, 2013. https://www.orcina.com/SoftwareProducts/OrcaFlex/ .../index.php 